\title{
Daniele Vitale*
}

\section{Entrevista:}

\section{Joubert José Lancha}

Arquiteto, professor doutor do Departamento de Arquitetura e Urbanismo da EESC-USP, Av. Trabalhador Sancarlense, 400, Centro, CEP 13566-590, São Carlos, SP, (16) 3373-9299, lanchaj|@sc.usp.br

\section{Miguel Antônio Buzzar}

Arquiteto, professor doutor do Departamento de Arquitetura e Urbanismo da Escola de Engenharia de São Carlos, Avenida Trabalhador Sancarlense, 400, CEP 13566590, São Carlos, SP (16) 33739294, mbuzzar@sc.usp.br

\section{Tradução:}

Nora Capelo

Arquiteta e urbanista, mestranda do programa de Pós-Graduação em Arquitetura e Urbanismo da EESC/USP, Avenida TrabaIhador Sancarlense, 400, CEP 13566590, São Carlos, SP, (16) 33739294, noracappello@yahoo.com.br

\section{Revisão técnica:}

Joubert José Lancha

risco Qual foi a sua relação com Rossi e qual é o papel de um mestre hoje?

\footnotetext{
* Daniele Vitale nasceu em 1945 em Muralto, Suíça. Formou-se em arquitetura pelo Politecnico di Milano em 1969, tendo como orientador Aldo Rossi. Iniciou sua carreira acadêmica trabalhando como assistente de Rossi, sendo desde 1976 professor titular de Composição Arquitetônica junto ao Politecnico di Milano. Ensinou ainda no Politecnico di Torino e em universidades de outros países, em particular, como "visiting professor" na Graduate School of Design Harvard, nos Estados Unidos.

Vitale procurou sempre aliar ao estudo da cidade, dos monumentos e da tipologia construtiva o trabalho de projeto e a elaboração teórica. Com Ignazio Gardella, um dos mestres da arquitetura italiana, colaborou em projetos
}

DV A minha relação com Rossi foi aquela de um aluno em relação ao seu professor, mesmo que a diferença de idade não fosse tão grande. Quando Rossi era meu professor ele era relativamente jovem e eu acredito ter sido seu aluno não de modo servil e com outras referências e com outras vicissitudes de formação. Mas foi para mim uma referência principal no plano intelectual e a minha relação pessoal com ele foi diferente ao longo do tempo: Rossi era uma pessoa muito complexa, muito rica e também muito difícil. E como para muitos outros, eu tive momentos muito felizes na minha relação com ele, de amizade e momentos de contraste. Rossi não era uma pessoa fácil, talvez exatamente por essa sua espessura, por essa sua densidade e também por essa sua suscetibilidade e por essa sua atitude não simples em relação aos fatos da vida e em relação às relações humanas.
Na minha opinião, a questão dos mestres é uma questão ao mesmo tempo importante e perigosa, isto porque a figura do mestre corre sempre o risco de cair no culto da personalidade. Mas eu acredito que os mestres de fato existam. Eu vejo Rossi ainda como uma das grandes figuras intelectuais do 900, como uma das principais figuras que construíram uma proposta e um trabalho autônomo e autêntico no campo da arquitetura. Isso deve ser reconhecido a ele: essa dimensão intelectual que era ao mesmo tempo capacidade inventiva e dimensão artística e capacidade de projeto, mas dentro de um quadro de elaboração global. Rossi nunca foi apenas arquiteto no sentido do artesão e, aliás, este aspecto do caráter artesanal, ou do saber fazer, foi nele secundário. Foi, ao contrário, uma importante figura artística e intelectual, de grande força figurativa e de grande capacidade de invenção. Mas os mestres, para nós, ao menos na cultura italiana, são algo diferente do arquiteto faber, do arquiteto que trabalha dentro de uma dimensão fabril, artesanal. Os mestres, para nós, foram figuras complexas, 
como o centro histórico de Gênova (de 1969 a 1974) e a Villa Eremo em Lecco (de 1984 a 1986). Participou, com Aldo Rossi, da XV e da XVI Triennale di Milano ("Architettura Internazionale" de 1973 e "Architettura/ Idea" de 1981). De 1978 a 1981 foi redator de "Lótus Internacional", uma das principais revistas da cultura arquitetônica européia. Dirige com Carlo Olmo a coleção de textos teóricos "I testimonidell'Architettura" da editora Allemandi de Turim. Publicou numerosos ensaios e artigos em livros e revistas internacionais, tratando de assuntos como a cidade européia, a arqueologia ou a arquitetura do racionalismo. De 1996 a 2000 foi membro do colégio docente de Doutorado em Composição Arquitetônica da Università luav di Venezia.

Figura 1: Aldo Rossi. atormentadas, ricas intelectualmente, de grande espessura cultural e que nos abriram horizontes em campos diferentes, não só em relação à arquitetura. Rossi na escola falava de muitas coisas diferentes: falava de cinema, de literatura, de arte e tudo isso reconduzia depois á arquitetura. Mas era uma visão ampla e Rossi dizia sempre que o seu destino de arquiteto estava, na realidade, ligado ao acaso, que poderia ter feito outra coisa, que poderia ter sido diretor de cinema assim como qualquer outra coisa. Eu acredito que isso se refira a cada um de nós: certamente podem existir elementos de vocação, de predestinação na historia de cada um, mas é verdade que cada um pode no fundo exercer tanto um trabalho quanto um outro e, fazendo-o, se apaixona e encontra as razões do próprio trabalho, do próprio viver e do próprio operar. E acredito que isso também tenha sido um ensinamento de Rossi. Ele era uma pessoa intensa, suscetível e que tinha em si um sentido trágico da vida e era ao mesmo tempo uma pessoa de grande densidade e de grande espessura humana.

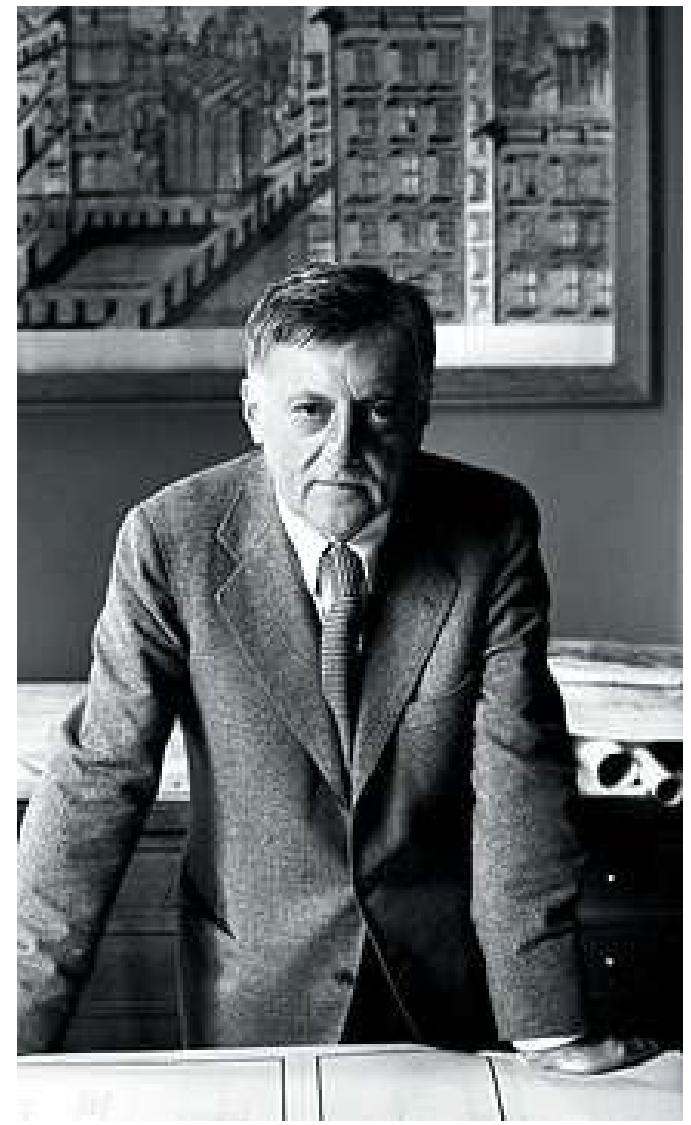

risco O senhor teve outro mestre, do qual falou em um artigo publicado na revista Risco: Ernesto Natan Rogers. Pode fazer uma comparação entre os dois mestres?

DVEram, na realidade, duas figuras muito diferentes. Rogers e Rossi foram contemporaneamente meus professores. No mesmo curso davam dois cursos paralelos mas ligados, junto com outros professores e eram duas figuras, acredito eu - mesmo que Rossi em certos aspectos fosse um aluno, um discípulo de Rogers - muito diferentes entre si. Rogers era uma figura nobre, arquiteto culto, sabia escrever, sabia construir a discussão, se rodeava de jovens, havia nisso uma sua generosidade muito grande, sabia identificar e escolher as pessoas e atribuirIhes responsabilidades: construiu em torno de si um grupo de jovens que depois constituíram a substância, o centro da cultura italiana no campo da arquitetura. Soube fazer de sua revista, que talvez tenha sido o território principal de seu ensino mais que a escola, um território de debate muito denso 
e muito fecundo também entre posições diferentes. Rogers tinha essa grande qualidade de não ser sectário. Mas eu acredito que a diversidade principal em relação a Rossi fosse uma espécie de incerteza que Rogers tinha com relação á arquitetura, exatamente por essa sua dimensão complexa e dialética de pensamento. Rogers conseguiu, no curso de sua existência, fazer alguns projetos também muito belos: para mim a sua invenção mais bela permanece sendo a Torre Velasca em Milão. Mas é como se cada vez recomeçasse do zero em seu trabalho, é como se cada vez repartisse à procura de uma linha de trabalho e de um mundo formal e isso talvez tenha marcado não apenas Rogers, mas também outros mestres da arquitetura italiana, importantes por essa sua dimensão de cultura de reflexão, mas ao mesmo tempo inseguros no terreno da arquitetura. Rossi era diferente. Rossi tinha uma espécie de universo obsessivo do qual partia, um mundo de figuras das quais era de certa forma dominado e que encontravam expressão em seus desenhos, em seus projetos: antes em seus desenhos depois em seus projetos e apenas às vezes e casualmente, quando conseguia, na construção. A construção nunca era o primeiro problema. O problema era exatamente esse mundo de figuras e de imagens que se amontoavam em sua mente, que se traduziam depois em croquis e desenhos, mas ele era, digamos, possuído por esse mundo interior e junto com isso acompanhava a reflexão o raciocínio. Mas algo não fechava na escola, no seu modo de ensinar: havia um ensino que Rossi queria sistemático, ordenado, racional, fundado nas coisas, que se referia à cidade. E havia um ponto de vista que em certos momentos foi quase naturalista com relação à cidade, como se estudar a cidade levasse ao projeto. E depois havia um outro ensinamento muito mais obscuro que para nós era difícil compreender, que era aquele que vinha de seus projetos e de seus desenhos, e as duas coisas nem sempre estavam de acordo ou se encontravam conciliadas, e apenas depois de muitos anos relendo A Arquitetura da Cidade talvez se encontrem os nexos e os contatos com aquele modo de desenhar, de pensar e de construir figuras de Rossi. Mas não era um ensinamento linear e no fundo era como se Rossi estivesse tomado por uma certa duplicidade em seu modo de trabalhar: por um lado esta vontade que vinha da herança do movimento moderno e do próprio Rogers de construir racionalmente a arquitetura, por outro um caminho totalmente pessoal em direção à arquitetura.

risco De que maneira o livro A Arquitetura da Cidade de Rossi se transformou em referencia para o pensamento e o debate arquitetônicos?

DV A Arquitetura da Cidade foi um livro muito importante, por certos aspectos improvisado e era um livro contraditório. É mais uma colagem que um livro unitário, um conjunto de textos e de trechos construídos no tempo, escritos às vezes com grande intensidade poética. Mas eu penso que não seja um livro que tenha densidade, é um livro que reúne muitas idéias diferentes, muitas observações e muitos estudos diferentes, mas eu acredito que seu valor consista nisso: primeiramente em uma capacidade de um olhar muito amplo sobre as questões da cidade. Rossi conhecia a fundo os textos da literatura européia, da sociologia, da economia urbana, da geografia, da historia e faz um uso deles muito tendencioso e deformado. O seu objetivo é aquele de fazer referência a um saber muito articulado, muito complexo e muito diferenciado à arquitetura. Mas a sua obsessão, o seu problema, é aquele de construir um texto de arquitetura. É um texto que não entra no mérito das escolhas projetuais e das escolhas formais, mas é um texto que vê a cidade como o terreno de uma fundação possível da arquitetura. Deve ser pensado em relação ao momento histórico e esse momento histórico era um momento de crise, de abandono das teses e de ausência de confiança nas teses tradicionais do movimento moderno, no funcionalismo e também na sua teoria com relação à cidade. Na realidade Rossi retoma um caminho antigo, que é aquele de pôr a cidade como referência primeira e de fundação em relação à arquitetura, talvez seguindo a lição do tratado de Alberti e de tantos outros tratados. Mas sempre existiram alternativas à idéia da arquitetura como construção, da arquitetura que se apoiava em fundamentos externos, em ilusões sociais ou em fundamentos sociológicos. Rossi pensa que a possibilidade seja aquela de relacionar a arquitetura à cidade e vê a cidade como a base teórica possível da nova arquitetura. Ele não diz exatamente como isso seja possível, mas no livro goteja como um equívoco possível e é um equivoco de tipo positivista. Rossi cita sempre quais eram os 
fundamentos teóricos de seu ensinamento e de sua posição. Falava do positivismo e dos grandes textos do positivismo, mas depois a lição do racionalismo em filosofia e em arquitetura, o marxismo, a grande questão do realismo como uma questão que tinha relação tanto o mundo da arte quanto com aquele da arquitetura mesmo que no mundo da arte havia chegado a um grau de esclarecimento e a uma intensidade de discussão muito maior que aquele acontecido para a arquitetura. Porém, do livro de Rossi nasce uma espécie de ilusão, isto é, que da referência e do estudo da cidade nasça quase por via linear um caminho possível e renovado à arquitetura e Rossi não desmentia com suficiente força ou com suficiente clareza este seu equivoco, e este equivoco será depois a base de uma sucessiva crise dos estudos urbanos. Na realidade a alternativa a este equívoco estava nos projetos de Rossi, mas isso não era tão simples de se entender naquele momento, quando o livro saiu, porque o livro saiu quando Rossi havia feito apenas seus primeiros projetos.

risco O senhor publicou uma edição revisada do livro de Rossi e no prefácio desta edição é citada uma frase de Borges que diz: "ninguém desce um rio duas vezes porque a água muda". Como o senhor vê o livro hoje, 40 anos depois da primeira edição de 1966 e 30 após a sua edição revisada?

DV Bom, eu acredito que o livro continue sendo um livro muito importante, apesar daquilo que eu dizia antes, isto é o seu caráter de uma grande colagem. No fundo os livros importantes do 900 no campo da arquitetura são relativamente poucos e deveríamos falar de Por Uma Arquitetura de Le Corbusier, dos escritos de Loos e depois de muitos outros evidentemente, mas na minha opinião o livro de Rossi está em uma posição eminente e junto ao livro de Rossi talvez aquele de Robert Venturi, Complexidade e Contradição. Mas eu acredito que seja como tempo de balanços e que os livros fundamentais de um tempo nunca sejam muitos, mas que devam ser reconhecidos e não é simples reconhecê-los. Na realidade eu leio $A$ Arquitetura da Cidade junto com o outro livro de Rossi. Rossi escreveu e publicou muito: era um escritor. Era um escritor estranho porque escrevia de maneira aparentemente linear e simples. Aquela de Rossi é uma escrita em aparência plana. Na realidade é uma escrita muito complexa e difícil de entender, porque procede por saltos e por acostamentos analógicos. Não há continuidade de raciocínio e não há encadeamento nos pensamentos. Isto, por exemplo, o distingue muito do modo de escrever de Rogers, que, ao contrário, tinha um modo fluente, elaborado e encadeado de escrever. Portanto aquele de Rossi é ao mesmo tempo um modo coordenado e analógico de escrever. Mas eu estava dizendo que Rossi escreve um segundo livro, que é como o oposto da arquitetura da cidade. Rossi dizia que era característica do bom artista, do bom intelectual, a insistência sempre nos mesmos temas, até a fazer deles uma obsessão e para mim ele tinha razão. Nisto remontava e frequentemente citava Sêneca. Mas acredito que Rossi mude de ponto de vista, porque é atravessado pela vida, por uma vicissitude pessoal difícil, por uma sua paixão profunda pela arquitetura; constrói seus desenhos e seus projetos como uma única coisa; dá, no fundo, pouco peso ao construir, mesmo que de um certo ponto em diante construa e muito, mas muda de atitude e a mudança principal de atitude para mim está no abandono, na consideração do caráter falacioso daquela posição que no fundo $A$ Arquitetura da Cidade deixava transparecer e era aquela posição que antes chamei de naturalística, isto é, a idéia de que a cidade seja um terreno tão rico e tão fecundo que contenha em si o projeto e portanto é como se houvesse uma razão geral do projeto, de fundação, da qual o arquiteto deve ir em busca. No final Rossi descobre que não são as grandes teorias ou os pensamentos gerais aqueles que podem constituir a arquitetura e o seu caminho, mas que a generalidade está não tanto dentro de um pensamento organizado e sistemático, quanto também através de caminhos e experiências pessoais e dentro da experiência pessoal reencontra a generalidade das coisas da arquitetura e a reencontra em um sentido e com significados diferentes em relação àquilo que transparecia da Arquitetura da Cidade. Assim, a Autobiografia Científica, que é um seu livro muito pessoal, um livro no qual em substância fala de si e de sua relação pessoal com a arquitetura, acredito que se torne uma outra grande lição que deve ser lida junto com $A$ Arquitetura da Cidade. Eu penso que deveríamos olhar os dois livros em sua desunião e ao mesmo tempo em sua unidade, como se estes fizessem corpo e fossem em seu complexo. Em seu conjunto a mensagem de Rossi, a mensagem que ele deixou. 
Naturalmente junto com os projetos, mas ao lado dos projetos, porque a escrita não coincide com os projetos, mas constitui um outro mundo de pensamentos e de elaborações.

risco Rossi, em uma aula inaugural junto ao CISA, falava de uma educação palladiana e depois isso se tornou um texto. Talvez este livro de Rossi seja o livro faltante de Palladio sobre a cidade no Tratado. O que o senhor acha?

DV Parece-me um pouco audaz. O que é certo é que Rossi era um grande admirador de Palladio e que falava dele muito freqüentemente. De Palladio admirava várias coisas. Dizia continuamente dessa sua estupefação por como os Quatro Livros tivessem se difundido no mundo todo e por como a arquitetura palladiana tivesse se tornado uma arquitetura internacional. Mas, sobretudo, era tocado - e continuava a repeti-lo - por como os edifícios de Palladio, repetidos em outros contextos e, como obviamente não pode deixar de ser, com diferenças, se tornassem outra coisa. Mas este é talvez um ponto do qual ainda falaremos. Mas é a idéia de Rossi: que a repetição nunca repete, que a repetição constitui sempre um outro fato e uma outra coisa e isso antes de tudo o tocava, Rossi via isso na vicissitude de Palladio: esse transformar-se de uma mesma coisa, de uma mesma idéia, em mundos diferentes, como se uma mesma idéia pudesse constituir realidades efetivamente diferentes entre si. Este é um aspecto. Eu acredito que o outro aspecto que o tocava e do qual em certo sentido se apropria, é uma capacidade de manipulação dos elementos, como se o patrimônio da arquitetura fosse um patrimônio muito denso, muito rico e muito articulado, e o arquiteto tivesse a possibilidade diante de si de colocar em relação mundos e tradições diferentes. Palladio constrói sua arquitetura em relação ao mundo antigo, que é, ao mesmo tempo, um mundo revirado e totalmente diferente daquele que ele vem constituindo em seus projetos, mas o faz, a cada vez, com grande capacidade de invenção, de combinação, de reconstituição de mundos formais diferentes. Eu acredito que Rossi tenha aprendido com isso e que em seus projetos se encontre uma capacidade ao menos análoga e similar.

risco Falando dos procedimentos artísticos e arquitetônicos, Rossi dá grande peso à metáfora.
Define-a como a transformação artística de uma palavra e de uma frase. Na realidade, parafraseia Quintigliani, que a interpretava como o mais belo entre os equívocos. Em arquitetura, sublinhava o deslocamento dos significados em Palladio ou a passagem dos elementos de uma função a outra. Creio que esta operação de deslocamento de elementos e de significados se confunda com as memórias pessoais e coletivas, permitindo a Rossi uma inventividade fecunda. Mesmo assim, de suas obras fala-se como de uma obra repetitiva e limitada. O que o senhor pensa disso?

DV Em primeiro lugar, me vem à mente uma frase que Rossi diz em sua Autobiografia, isto é, que procuramos sempre uma coisa, mas sabemos que não procuramos apenas aquela e, certas vezes, a outra coisa que procuramos não é clara ou não está presente para a consciência, mas sempre procuramos alguma outra coisa junto com aquela que nos parece que queremos procurar. Eu acredito que isso aconteça sempre, isto é, que a explicação racional e as motivações que nós damos do nosso trabalho nos acompanhem e sejam importantes, mas ao mesmo tempo nunca expliquem inteiramente. Isto é, as motivações autênticas são sempre mais densas mais complexas e diferentes em relação ao que nós imaginamos. E depois, Rossi acreditava nessa capacidade de usar com desinibição os elementos da história e da arquitetura. Mas talvez aquilo que o distingue também da pesquisa do próprio Palladio seja uma espécie de pesquisa da essência ou do esqueleto. Antes falávamos dessa capacidade de manipulação que existe em Palladio e existe, em certos aspectos, também em Rossi. Palladio usa com desinibição elementos e tradições diferentes, por exemplo, dessacraliza a igreja, recompondo-a usando os elementos tanto do templo clássico quanto por exemplo da casa antiga. E cumpre esta operação em planos diferentes e em temas diferentes. Eu acredito que aquilo que distingue Rossi seja uma atitude tendenciosamente articulada em relação à arquitetura, talvez este modo de operar se modifique no tempo e na fase última de seu trabalho. Mas Rossi pensa que a arquitetura não deva constituir-se necessariamente: nisto remonta à lição dos iluministas por encadeamentos ou por sistemas de subordinações de elementos. Nisso aprende, por exemplo, de Emil Kauffmann, de sua análise dos projetos dos iluministas. Mas é 
como um caminho que escolhe instintivamente e que depois encontra-o explicado por Kauffmann e pela lição dos iluministas. Isto é, a arquitetura de Rossi é uma arquitetura tendenciosamente articulada, que se constitui por elementos e onde os elementos são sempre elementos nus e há uma espécie de busca das coisas constitutivas, das coisas primeiras e das formas primordiais. É uma atitude diferente em relação àquela muito mais formalística das vanguardas ou dos artistas ou da arquitetura moderna, que estavam sempre à procura das formas originárias. Trata-se, ao contrário, de uma busca de arquétipos de fundação e, ao mesmo tempo, de uma constituição do edifício e do projeto em termos sintéticos, isto é, Rossi dá grande peso, na realidade, à imagem. A imagem é a força o projeto e do edifício, e a força da imagem depende também deste seu caráter esquelético, desta sua sobriedade. Mas Rossi, ao mesmo tempo, pensa que esse caminho não seja geométrico, isto também o distingue das vanguardas, isto é, a busca de elementos simples não é uma busca no plano da geometria apenas, tanto que a natureza dos elementos se encontra nas próprias coisas. É um pouco como se dentro das paisagens, dentro do mundo constituído das coisas, dos objetos, das cidades, devesse se buscar uma espécie de estrutura e de verdade ou realidade escondida, e dali devesse ser extraída até a repetição. Rossi, na parte final da sua história de arquiteto cita, isto é repete, mas faz isso de uma maneira análoga e diferente daquela de Loos. Loos também citava, isto é, colocava dentro de suas arquiteturas fragmentos de arquiteturas de um outro tempo ou de um outro mundo. Em Loos isso está ligado a uma impossibilidade que é aquela, por exemplo, de repetir os elementos clássicos a não ser em certas circunstâncias e em certos lugares. Em Rossi trata-se de uma impossibilidade diferente, da constatação de que é impossível chegar ao mesmo grau de prenhez no definir das formas, e que esta completude já foi conquistada pelo mundo do real através da experiência que se acumulou nos séculos e que passou através da evolução das coisas e dos edifícios. Assim não resta que citar, porque a citação permanece em certos casos a forma mais eficaz e mais potentemente sintetizador para evocar uma realidade à qual não se consegue chegar por outro caminho. Mas isso pertença talvez à história do Rossi tardio, isto é, uma espécie de renuncia que leva à repetição e à citação. risco Falar de Rossi sem falar de seus desenhos ou da importância do desenho em seu contínuo trabalho de elaboração sobre a arquitetura seria imperdoável. Braghieri afirma que em Rossi o desenho nunca é fim em si mesmo, é sempre arquitetura, porque reflete uma condição, um momento da própria vida, da realidade, o contínuo redesenhar os elementos fixos, quando escolhe um lugar torna-se arquitetura. Qual é a sua interpretação dos desenhos de Rossi?

DV Eu penso que os desenhos de Rossi sejam importantíssimos e também muito belos e que estejam isentos de formalismos. Não pertencem, mesmo que tenham adquirido um grande valor comercial nas galerias e no mercado, àquele fenômeno da ilustração no campo da arquitetura que teve tão grande difusão e àquele exercício do desenho como ilustração ao qual se aplicaram tantos arquitetos. Eu penso que o desenho de Rossi seja um desenho fortemente inovador e inventivo, isto é, introduz uma idéia diferente do desenho e da idéia do desenho no imaginar a arquitetura. Os desenhos de Rossi têm, na realidade, uma existência autônoma: não são nem seus edifícios nem suas construções nem seu pensamentos e seus escritos. São uma outra coisa. O desenho dos mestres da arquitetura moderna era um desenho mais ou menos hábil e eficaz, mas era em geral um desenho de observação. No fundo também os cadernos de Corbusier são desenhos de observação, são cadernos de viagem nos quais Corbusier, com grande habilidade, com grande prenhez esboçava aquilo que via e que o tocava, e estes desenhos em seu conjunto, mesmo partindo das realidades observadas constituem um mundo formal e são o fundamento do projeto, mas pertencem ao mundo da observação. Aqueles de Rossi não, eu acredito que pertençam muito mais ao mundo da imaginação da arquitetura. São quase sempre desenhos de aproximação, isto é, que tentam aproximar figuras diferentes. Às vezes nascem de situações subjetivas, se constroem e torno de temas obsessivos, por exemplo, aquele da janela de fora, de dentro, ou aquele da casa abandonada, ou das paisagens da cidade e da cidade industrial e da periferia. Rossi era dominado por estes temas. Mas é como se eles se recompusessem reinventando possibilidades da arquitetura. Rossi freqüentemente sobrepõe fatos diferentes: desenha um seu projeto e atrás coloca 
um monumento, a paisagem de uma cidade industrial, a catedral de Milão, alguma outra referência de arquitetura. Isto tem a ver também com a capacidade ilustrativa do desenho. Algumas pranchas de projeto - é necessário fazer uma distinção entre os croquis pessoais de Rossi e suas pranchas - são também, na realidade, colagens. Por exemplo, Rossi nisto retoma modos de desenho antigos, como o modo de desenhar de Schinkel. Schinkel tinha esta habilidade extraordinária de resumir um inteiro projeto dentro de uma única prancha. A prancha dizia qual era a relação do edifício com a paisagem, como era constituído o edifício, porque, em geral, havia plantas e cortes, mas definia também a arquitetura, isto é, dizia qual era o edifício no plano dos materiais ou do detalhe e o todo estava como que encerrado dentro de uma só figuração, uma figuração unitária. Rossi tem esta mesma capacidade em muitas pranchas de projeto. Não sempre as pranchas são inteiramente desenhadas por ele, mas são sempre concebidas e pensadas por ele e a esta capacidade de restituição sintética do projeto acrescenta uma série de aproximações analógicas que o explicam através de outro caminho, por outra via, aproxima outros Figura 2: Desenho de Aldo Rossi, 1979 edifícios ou paisagens ou elementos da cidade que explicam qual é a raiz, a motivação profunda do projeto e, portanto, devemos distinguir entre estes planos diferentes do desenho de Rossi: o croqui rápido, o croqui pessoal e às vezes trágico que reflete também um sentimento ou um momento da vida, o desenho de imaginação de arquitetura e, por fim, as pranchas de projeto. Eu acredito que as pranchas de Rossi nunca sejam pranchas técnicas mesmo quando têm um objetivo de definição técnica, mas conservem sempre um forte caráter figurativo. Freqüentemente os desenhos técnicos perdem este caráter figurativo e não sempre a precisão técnica é uma base suficiente, como no desenho dos engenheiros, para a construção de um mundo figurativo. Às vezes, os desenhos das máquinas têm uma sua profunda beleza. Mas, na minha opinião, Rossi nunca pensa o desenho como uma espécie de dispositivo ou mecanismo, ma o pensa sempre em sentido figurativo e, portanto, como uma espécie de quadro. Aquela de Rossi é em sentido próprio uma espécie de pintura, mesmo que não use os instrumentos do pintor ou os pincéis, mas eu creio que Rossi se aproprie dos utensílios de trabalho e que nesta sua capacidade áspera de restituição dos conteúdos e da essência daquilo que quer dizer, daquilo que quer figurar, eu penso que possa de verdade ser aproximado àquele que talvez seja o maior pintor italiano do 900: Sironi.

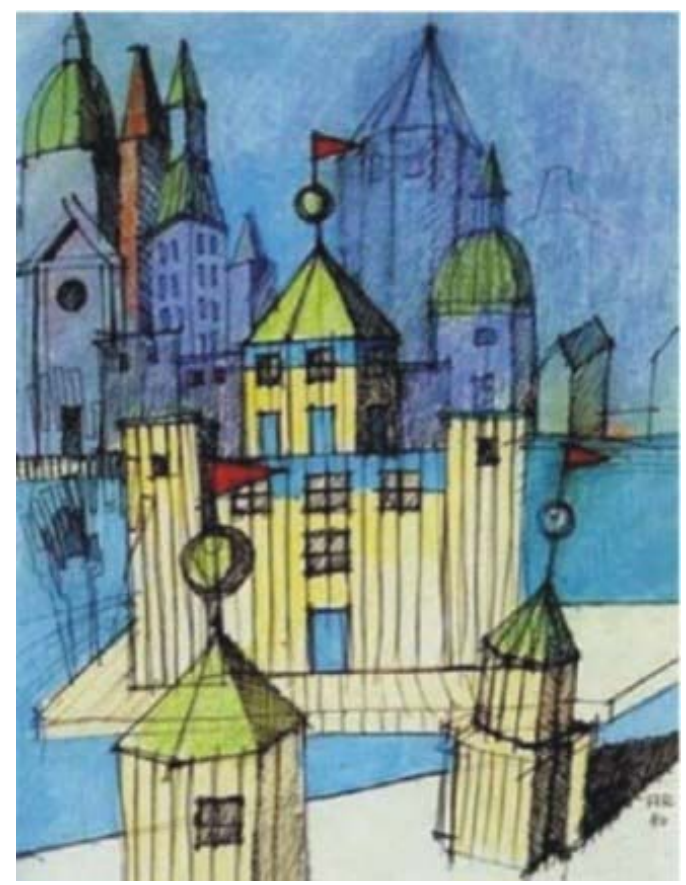


Assim como em Sironi, o desenho de Rossi consegue não ser quase nunca formalista, mas é sempre um desenho duro e que vai ao cerne, ao esqueleto das coisas, como um desenho osteológico digamos, que põe em evidência sempre a substância profunda das coisas

risco Quais são os projetos que admira de Rossi ou quais são os projetos que expressam de forma mais evidente o seu pensamento?

DV Bom, trata-se de preferências pessoais na realidade. Posso dizer quais são os projetos de Rossi que amo mais ou sobre os quais mais fundei minha formação e que mais me influenciaram no plano pessoal. Entretanto, eu acredito também os primeiros projetos, isto é, aqueles que têm ainda um fundamento purista. Um projeto belíssimo é aquele do Monumento à Resistência de Cuneo, mesmo que seja um projeto que o mundo de Rossi superará. Parece-me um projeto, sendo um grande cubo escavado de maneira muito densa e com grande capacidade figurativa, um projeto ainda muito belo e muito denso. E depois para referir-me ainda ao Rossi em certo sentido racionalista ou purista, eu acredito que poderia falar da Stecca do Gallaratese, a unidade de habitação do Gallaratese, cuja força está também na contraposição à arquitetura de Aymonino, mas que está dentro de uma linha da arquitetura milanesa: aquela linha que recolhe a tradição da casa pobre, da casa popular, combinaa com a pesquisa racionalista sobre a casa lógica, da casa construída com exatidão, e produz obras de grande eficácia e de grande força figurativa. Eu creio que a casa de Rossi venha da casa de Pollini no bairro Harar, da casa de Giancarlo de Carlo em Sesto San Giovanni, da casa de Lingeri no QT 8, isto é, tem uma série de precedentes racionalistas atrás de si, dos quais parte e coloca de novo em relação com a casa popular, da qual aqueles projetos racionalistas haviam se afastado às vezes por excesso de purismo. Mas depois eu acredito que um dos mais belos projetos de Rossi permaneça sendo aquele do Cemitério de Modena. Permanece no sentido da capacidade evocativa, na capacidade de combinar imagens diferentes e, ao mesmo tempo, de dar-lhes um significado profundo e essencial. Rossi olha para a periferia e toma como sinal de morte, mas também como sinal esquelético da constituição da arquitetura, a casa vazia, que nas paisagens de periferia é sempre encontrada e colocaa ao centro do cemitério. Ao mesmo tempo, o cemitério tem uma espécie de figuração osteológica: é como se a espinha de peixe que Rossi reproduz no interior do museu fosse quase uma espécie de costela de Cristo. Enfim, há uma capacidade muito poderosa e não diretamente simbólica de assumir elementos figurativos e de recompô-los nesta idéia da cidade e da casa dos mortos. Eu creio que permaneça um dos seus projetos mais eficazes e mais belos no plano compositivo também, no sentido da capacidade de usar elementos muito diferentes para construir uma paisagem urbana: eu vejo o cemitério de Modena como uma espécie de cidade e de proposta potencial para a cidade. Mas as cidades, dizia Rossi, são ao mesmo tempo acampamentos de mortos e de vivos e o seu cemitério é um acampamento dos vivos. E depois há alguns projetos residenciais de Rossi muito belos e de seus projetos berlinenses eu amo particularmente o primeiro projeto, aquele que ele constrói na esquina da Friedrichstrasse com a Hauchstrasse, porque é novamente um projeto que se constitui numa idéia elementar; assume o tema que Berlim então propunha, que é aquele do quarteirão, mas reduz a casa a alguns elementos essenciais: a torre e os elementos intermediários que ligam as torres. É um projeto construído analiticamente - este caráter analítico seja talvez uma das características desde sempre da arquitetura racional-, mas é como se aqui, como em outros seus projetos, Rossi conseguisse transfigurar o caráter analítico e racional dos projetos no sentido de uma espécie de exaltação. Na sua introdução a Boullée, falava do racionalismo convencional e do racionalismo exaltado e relacionava esta definição aos grandes projetos e às grandes imagens de Boullée. Mas eu acredito que em muitos de seus projetos Rossi alcance este estágio ou de condição da exaltação. E talvez esta casa de Hauchstrasse chegue nisso e seja um de seus projetos mais belos. E depois há os projetos de teatros de Rossi: o Teatro del Mondo que é, em sua pequenez e em seu caráter efêmero, um edifício destinado a vida muito breve, feito de tubos de canteiro de obras e de revestimentos lígneos. É um edifício flutuante, não obstante, acredito que aquele pequeno edifício se torne uma proposta para Veneza. E se torna isso num sentido singular, no sentido da recusa do caráter pictórico, transitório e indefinido da cidade e de suas atmosferas e, portanto, a recusa 
do pitoresco e também da decadência da cidade. E Rossi, em seu projeto do Teatro del Mondo, eu acredito que volte a ser palladiano, isto é, como Palladio constitui um organismo que é, na realidade, fortemente estruturado e construído segundo um mundo formal concluído, como havia feito Palladio em seus edifícios que davam para a bacia de São Marcos, que se tornam como "pontos fixos" dos quais esta paisagem indefinida e vaga se refere e o estrutura, o organiza a partir de seu interior. No fundo, Rossi nos diz que não é perseguindo este caráter da labilidade veneziana que é possível intervir em Veneza, mas que há outro caminho que é o mesmo de Palladio. E depois há os outros grandes projetos de teatro: o teatro de Genova, o Carlo Felice, que eu considero um projeto belíssimo e que talvez seja o projeto mais à la Boullée de Rossi, isto é, a transfiguração também formal dos elementos da cidade torna-se a força do projeto e sua capacidade de se impor. Rossi assume um caráter da cidade que é um caráter volumétrico - Genova é uma cidade cubista, feita de volumes e de objetos isolados - e dando grandíssimo relevo, grande força e grande dimensão à parte técnica, ao corpo técnico, portanto ao palco do teatro, faz dele uma espécie de grande torre que domina a cidade e que também se torna um elemento sintetizador em relação à história da cidade e a seu caráter figurativo. É como se o grande cubo de Rossi que domina a Genova oitocentesca, a Genova histórica, a Genova antiga, retomasse os palácios isolados em forma de paralelepípedo ou de cubo da Strada Nuova de Genova também na modalidade concreta, também neste gigantesca moldura que limita o cubo em direção ao alto, em direção ao céu, e que dá força e capacidade figurativa a este teatro. E depois o teatro La Fenice, esta citação felicíssima que no interior Rossi faz da Basílica Palladiana: Rossi reproduz no foyer do teatro um pedaço da Basílica de Palladio e eu creio que seja extraordinária e muito eficaz esta sua escolha. E ao mesmo tempo em que consegue fazer do teatro um elemento de novo sintetizador e que entra em diálogo e em relação com a história do Veneto e da arquitetura veneta e veneziana. E depois ainda certas instalações cenográficas teatrais de Rossi, como, por exemplo, aquela instalação belíssima que fez em Toronto, uma espécie de fantástica cenografia construída, de instalação teatral que dá para o Oceano, na qual Rossi retoma elementos efêmeros, mas também a arquitetura dos faróis, e de novo aqui há uma capacidade figurativa muito sumária e muito poderosa. E naturalmente muitos outros projetos ainda, mas talvez citei aqueles que para mim são fonte maior de sugestão e também de preferência pessoal.

risco Dez anos depois da morte de Rossi, sua obra continua influenciando arquitetos?

DV Eu acredito que não tanto se olharmos para a presença de Rossi e de seus livros no quadro da discussão atual da arquitetura. Os livros de Rossi continuam sendo lidos na escola, continuam sendo reimpressos e tendo certa divulgação. Ao mesmo tempo, Rossi é uma figura relativamente esquecida. Talvez o decênio de sua morte sirva a trazê-lo de volta à luz, a fazer dele de novo um elemento de uma discussão, porque eu acredito que aquela de Rossi seja uma posição de substância e que, portanto, tenha uma sua capacidade de duração, tenha a capacidade de atravessar o tempo. Parece-me que não pertença aos fenômenos efêmeros das modas, aos fenômenos passageiros das figurações que duram o ciclo de uma estação e depois passam. E, portanto, eu acredito que a obra de Rossi ressurgirá e que não conte tanto a fortuna momentânea. Rossi gostava muito da estátua da Fortuna que está na Ponta da Alfândega em Veneza e que roda sobre si mesma, segundo a direção dos ventos. Eu creio que conte pouco a fortuna ou o sucesso dos arquitetos. Rossi passou um período muito longo de escuridão, no qual foi contrariado pela cultura arquitetônica, no qual foi hostilizado: era ao mesmo tempo muito odiado e muito amado, mas amado e entendido por um círculo relativamente limitado. Mas creio que tudo isso conte relativamente pouco, isto é, como se sucedem as fases, os ciclos da sorte e do azar. O que conta são as motivações profundas e os conteúdos de uma mensagem. E eu creio que a mensagem de Rossi permaneça e seja destinada a ressurgir, e como tudo ressurgirá em modos diferentes, não mais segundo certas interpretações literais, não mais será entendido como foi entendido por outras gerações. Mas acredito que aquela de Rossi seja uma lição destinada a durar no tempo e, portanto, a repropor-se em termos diferentes no tempo. Não quero dizer como se repropôs aquela de Palladio, porque evidentemente são incomparáveis as duas figuras, mas Palladio também 
conheceu sortes e azares e, sobretudo, constituiu mundos formais inteiramente articulados e diferentes ao longo do tempo. O modo de durar de um arquiteto é sempre diferente e eu acredito que aquilo que importe de Rossi seja ao mesmo tempo o mundo figurativo, seu modo de desenhar e sua imaginação da arquitetura através do desenho, algumas de suas obras construídas e aquilo que deixou escrito, isto é, uma espécie de mensagem geral que em seus textos se revela profunda e que eu acredito continuará influenciando o curso do debate e da pesquisa em arquitetura.

risco Para terminar: qual é a presença de Rossi em seu ensino e em seus projetos como arquiteto?

DV A respeito disso eu tenho certa resistência em falar porque acredito que Rossi não tenha intérpretes mais ou menos fiéis, ou talvez sim, talvez as pessoas que trabalharam por muitos anos com ele, em relação direta com ele. Mas o problema não é aquele da fidelidade: cada um recolhe de uma maneira diferente, segundo um caminho próprio, o ensino de outros. Eu creio que a riqueza de Rossi tenha estado exatamente em ter gerado caminhos diferentes para a arquitetura. Eu acredito que de Rossi aprendi a ser professor, sinto-me mais seguro nisso: aprendi a montar as aulas, a pensá-las, a construí-las, a ler e a ver a arquitetura como uma construção ao mesmo tempo intelectual e figurativa.
E também em relação aos meus projetos eu sempre tive certo pudor: eu projetei em certos momentos de maneira mais intensa, em outros abandonei o projeto para dedicar-me mais à escrita ou à escola. Não creio que caiba a mim avaliar os meus projetos. Creio que também dentro de meus projetos esteja a lição de Rossi, a busca da relação com a cidade, a busca de uma figuração essencial, mas exatamente é uma mensagem e um modo de trabalho que pode ser recolhido de maneiras muito diferentes e que cada um contamina com outras experiências e outros caminhos. Para mim foi importante também o estágio que fiz no escritório de Ignazio Gardella, que é uma outra figura de arquiteto muito diferente de Rossi, ao mesmo tempo afim e muito distante e creio que na minha experiência tenha pesado muito também o ensino de Gardella, estar em contato com seu trabalho, com seu modo de projetar e com suas obras. Mas acredito que esta seja uma reflexão autocrítica. No final não cabe a cada um de nós avaliar aquilo que fez. A cada um de nós cabe, isso sim, falar dos próprios trabalhos, porque deve ser quebrada esta interdição pela qual não se pode falar dos próprios projetos. Acredito que se possa falar dos próprios projetos, mas falar dos próprios projetos e explicá-los e comentá-los é diferente de julgá-los e avaliá-los. Acredito que isto caiba mais a outros e também encontrar nexos e ligações que talvez para nós mesmos sejam obscuros ou nunca estejam inteiramente presentes. 